\title{
Best Interest of Child Assessment and Spouse Violence Towards Other Partner in Determent of Parental Custody from the Court in Albania
}

\author{
Ma. Florion Bejleri \\ Tirana University, Faculty of Social Sciences \\ Email florionbejleri@yahoo.com
}

Doi:10.5901/ajis.2015.v4n2p203

\begin{abstract}
This article aims to identify if the spouse violence is considered as an influencing factor by the court while taking the decision determining the parental custody after the divorce in Albania. The importance of this article lies on the fact that it may serve to unify the work practice of judges related evaluation of the parental custody, based on best interest of child principle. Through qualitative method have been completed 12 semi-structured interviews with 4 judges (from the family section) on three different district courts of Albania (Tirana, Durres and Vlora). According to the findings resulted that judges mostly consider spouse violence as a separate issue which do not necessarily influence in determining parental custody of the child after divorce. Judges believe that domestic violence is a different issue and should be treated by the penal law while parental custody is treated by the family law. In conclusion, the research highlights that spouse violence committed from one partner to the other is not considered a constitutive element on evaluation parental custody because of a gap in the legal framework. Each parent can have the custody of child dispute abusing towards other parent. Theory suggests that spouse violence mast be a determinant factor of evaluation and final court decision of parental custody. It is recommended to create a special law related best interest of child that will contain all factors including spouse violence, in order to help judges to evaluate and take the right decisions on determine parental custody after the divorce.
\end{abstract}

Keywords: Best interest of child, spouse violence, parental custody, court decision, divorce.

\section{Introduction}

During the divorce process the court must decide on parental custody. Parents present their arguments in order to gain the right of custody. In some cases during the trial, it is often found that one partner has committed violence against the other partner and meanwhile the court proceeds in order to evaluate which parent is going to take the parental custody based on the best interest of child principle.

According to Tirana District Court data for year 2014, in 98\% of the cases where couples seek the divorce, it has resulted that one of the following types of violence (physical, psychological, economical, sexual) has been committed from one spouse partner to the other.

The violence has resulted not only in marriage dissolution but as well in creating a bed parenting model for children who have been testimonies during the conflicts and continuous abuse from one parent to the other.

An abusive spouse is seen to be an inappropriate role model for children and may inflict direct abuse on the child given the overlap of partner violence and child maltreatment (Edleson, 1999).

Despite this fact, during the divorce process both parents seek the main parental custody for the children and the court must evaluate which one of them will fulfill better children's need, desire and perspective. The court must decide which of the parents must have the main parental custody based on the courts conviction after an evaluation process and evidences.

The whole process relies on adult discretion to judge children's developing competencies (discretion being the appropriate word because 'competency' is nowhere clearly defined (Sawyer, 1997). The court is based on the evaluation report, which is prepared by a social worker or a psychologist who should bring clear evidences, arguments and recommendations related the parents that fulfills better the children's best interest principle in order to gain the right of parental custody. On the evaluation process the court directs the evaluation experts regarding the facts, circumstances, actual situation and factors influencing the children development which must be considered.

According to the secondary data of the Tirana District Court for the year 2014 it results that in $85 \%$ of the cases reviewed by the court for marriage dissolution, has been found that physical violence has been used by one spouse to the other. 
This fact indicates an important issue is raised at this point: Does the judges consider the committed violence from one spouse to the other, as a crucial element for determining which parent should get the parental custody or they consider this issue separately?

While during the parenting a behavioral model between parents and children has been created, what would be the consequences for the children if the parental custody will be granted to the parent who has continuously committed violence to the other parent?

The purpose of this article is; to identify the fact that, the committed violence by one spouse of to the other is considered an influencing factor to the court decision for determining the parental custody after the divorce in Albania.

Through this scientific research will be identified the perception of judges related the impact that violence committed by one spouse to the other has on children and to this meaning, to identify the evaluation method of the children's best interest principle.

\section{Literature Review}

\subsection{Domestic violence committed by one spouse to the other}

Domestic violence in Albania (including the violence committed by one spouse to the other) is sanctioned by a special law. (Law 9669 dates 18,12,2006 "On measures against violence in family relationship" This is an administrativ-civil law, and aims to prevent and reduce the domestic violence, through appropriate legal measures. The law aims to implement special protection for women, children, elderly people and people with disabilities, who may be victims of domestic violence. The law defines the meaning of domestic violence, cases and the ways it is committed and it defines besides concrete actions of prevention, even the responsible institutions that will interact in order to stop the violence and help its victims. Within the meaning of article 3 of this law, the term "violence" is defined and contain; "every actions or non commision of a person against another person, resulting in violence of physical, moral, phsycological, sexual, social and economical integrity". "Domestic violence" is defined as: "any act of violence committed among persons which are or have been in familiar relationship". According to Article 3, paragraph 3 of the Law, in "family members" are included: "the husband/wife or the cohabitee, or ex-wife or ex-husband, or ex - cohabitee, brothers, sisters, those related in the first degree, including adoptive parents and adopted children".

This law implements the protection of the abused spouse by forcing the abusive spouse to stop the violence and in some cases by prohibiting the abusive one to get near the conjugal apartment or to physically contact the abused spouse.

This law does not provide sanctions related custody of children in case of divorce for the abusive spouses.

In 2012, several changes were made to the Criminal Code of the Republic of Albania, where domestic violence is considered a criminal offense. Beating, as well as any other act of violence against the person who is the spouse, exspouse, cohabitee or ex-cohabitant, related in the first degree or close family-in-law with the offender, resulting in the violation of physical, psycho-social and its economic integrity, is punished with imprisonment up to two years. Serious threat to cause death or serious injury, against the person who is the spouse, ex-spouse, cohabitee or ex-cohabitant, related in the first degree or close family-in-law with the offender, resulting in the violation of his/her mental/psychological integrity, is punished with imprisonment up to three years. Intentional injury, of the person who is the spouse, ex-spouse, cohabitee or ex-cohabitant, related in the first degree or close family-in-law with the offender, that has caused temporary incapacity to work more than nine days, is punished with imprisonment up to five years. (Criminal Code Article 130/a). The same acts, if committed repeatedly, are punished with imprisonment from one year to five years. (CCA 130/b)

There is no law or any specific article in the Albanian legislation that might guide the court regarding the parental custody for the spouse who has committed violence against the other parent. This decision remains a matter of subjective appreciation of the judges. In some jurisdictions of United States exposing children to partner violence is considered a separate criminal offense, and in other states exposure to partner violence can activate the intervention of the child protection system (Edleson, 1999).

Only if the victim of domestic violence has demanded a "protection order" which is a court decision compelling the abusive spouse to stop the violence and to respect the preventive measures set by the court (under Article 10 of Law No. 9669 "on the protection from violence in family relations) then the court may oblige the perpetrator to participate in rehabilitation courses for changing his behavior, but in the cases where a protective order is not required by the victim, then the violent parent is not involved in any education program for the prevention of violence or the factors that influence his aggressive behavior. 
Major innovations in family court promote parent education programs, mediation, and other alternate dispute resolution strategies to avoid the emotional and financial consequences of litigation and produce more cooperative parenting plans (Jaffe, Lemon, et al., 2003).

\subsection{Parental custody}

In adition to parenting responsibilities there are also risk factors which directly affect the children. Among the major risks of parenting is the marital conflict. (Knauth, 2001). According to the Albanian legislation "parental responsibility" includes the entirety of the rights and duties of the parents by taking care of the children in order to ensure emotional, social and material welfare and by maintaining personal relationship with the children, providing wellgrowth, education, legal representation dhe administering of children's property. (Article 2015 of the Family Code). Even the sense of parental responsibility is composed by general components in order to cover all stages of children's developement, in the sense of applying the children's best interest principle. Albanian Family Code provides the removal of parental responsibility by a court decision in cases when the parent abuses or shows negligence in parental responsibility, or the behaviour harms the education of the children. Removal of parental responsibility may be reuqired by the other parent, children's relatives or prosecutor in the court, in cases where the child is found in circumstances that directly affect his education, emotional and physical health as a result of non complying with the obligations that law imposes each parent. Removal of parental responsibility by the court means that the parent which affects negatively or irresponsively has no more rights to take decisions about the child/children for a specified period of time decided by the court. However the Albanian legislation provides the removal of parental custody responsibility for the above mentioned cases (when a parent abuses or does not fulfill the legal obligations towards children) but does not exclude the abusive spouse in cases of violence used against the other parent to win the parental custody after the divorce. This legal gap complicates the court decision not only in cases of domestic violence but even in family cases.

\subsection{Children's best interest principle and it's judiciary practices in Albania}

The application of this principle, in judicial case regarding family issues, has a significant importance. The Albanian Family Code does not express provisions regarding the meaning of "children's best interest principle", as it is considered as a general principle.

This principle is composed by many components that represent all the aspects of children developement and protection, therefore first of all it is the parents duty to understand which are the children's best interests. In cases when parents have conflicts between them, then the court intervenes to evoid divorcin. Mediation saves divorcing couples the experience of contentious courtroom battles and, in the most successful cases, provides couples with a schema for resolving future conflicts (Jessani, 2002).In judical practice it is often difficult for the judges to determine best interest of child especially in cases when parents came to the point of marriage dissolution.

The principle of the child's best interests was elaborated in the United Nations Convention "on the Rights of the Child" (1989, Article 9(3) which is ratified by Albania and became part of internal legislation. The typical cases when the implementation of this principle is required are those of marriage dissolution and appointing of the parent which will have the main responsibility for growing and education of the children after the divorce, cases of marriage dissolution by agreement, in actions and decisions related to wealth, in cases of children abandonement, adoption and custody. In many judiciary cases, the court decides to prevent one of the parents the "relationship with the child" as long as it poses danger and harms the children's interests. The court has the right to refuse the marriage dissolution by agreement, when it notices that such dissolution harms the children interests. In this case the courts provides 3 month's time for the spouses, to review the dissolution based on children's best interest. If this does not happen, then the court might dismiss the request and not accept the marriage dissolution. The children's interest include even the wealth.

The court desides for conveyance of real estate, borrowing on the behalf of a minor, pledge of a collateral, inheriting, testament and all other legal actions that threaten or protect the children interest are performed only by a court decision. Even regarding the adoption or the custody, the principle of children's best interest is applied (according to articles 240 and 248 of the Family Code in Albania). The court in each case might remove the custody of one parent and replace it with another, in cases where it noticed an intentional abuse or negligence which harms the children interests. 


\subsection{Evaluation proccess of the best interest of child}

Case law shows that applications of this principle require a greater involvement than simply engaging the court. For this matter it is necessary for social workers, psychologists and independent organizations operating in the field of child protection, to intervene and help. This intervention can be done directly through psychological reports that court requires by the psychologists and the social workers during the trial. These reports should contain the emotional state of the child, living conditions, family environment and relationship with each parent including other circumstances mainly set by the court, connected and analyzed from the perspective of the best interests of the child. Assessors must also submit the cases of where violence has been noticed and its effects on children. Before the court obtain a temporary or final decision regarding the manner of parental custody enforcement, the right to visit the child or according the rights of custody to one ex-spouse, must call a psychologist or social worker, who, before giving their opinion, should get information regarding the material and moral situation of the family, the conditions in which they live and where is most convenient for the child to live. If the court concludes that child should temporarily stay with a third person or in a foster family, must take the opinion of the sector of assistance and social services at the municipality of the town where the judgment takes place. (Article 155 of the Family Code of the Republic of Albania). Unlike Albania where "The Best Interests of the Child " standard is appreciated only by an article of the Family Code, each state legislature in the United States controls its own child custody law, and laws can vary considerably from state to state. Still, every state law indicates that custody decisions are to be made according to "best interests of the child" standard, the principle that judicial determinations should be based on each child's unique future best interests (Elrod \& Spector, 2004). During the evaluation process in accordance with his age and ability to understand, the child may intervene in any proceedings to give his consent. In all cases, when the child wants to be heard by the court, the judge is obliged to hear and cannot refuse his request (article 6 of the Family Code). Evaluation experts take also the opinion of the child during the interviews regarding the issue of custody after divorce but also in determining the overall family situation of the destructive factors including family violence exercised by one or by both parents. Additionally, complex cases involving the disintegration of a family unit, especially a family with a violent parent, are often fraught with a myriad of destructive factors such as alcohol abuse, suicide attempts (Ragin et al., 2002), drug abuse (Salomon, Bassuk,\&Huntington, 2002), depression (Carlson, McNutt, Choi, \& Rose, 2002), mental and physical health problems, career disruption, and financial crisis (Riger, Raja, \& Camacho, 2002). Abusive actions are a symptom of the cumulative interaction between historical and current stress and relationship difficulties. Denial, and the failure to take responsibility for abusive behavior, is an integral aspect of thinking which sees children as deserving of punishment, neglect, rejection or sexual contact. (Bentovim, A., Reder, P., Duncan, S, Lucey, C., 2003). Assessments are inter-agency and multi-disciplinary. Workers should work individually and collectively to produce assessments which provide the best understanding of parents and issues of child protection. Whilst the social worker might be seen as the lead worker or key worker, other professionals have crucial contributions to make (Fowler 2003). In the evaluation process the emotional relationship of the childrens with the parents has an important role. The parent's emotional relationship with the child includes their feelings towards the child, both positive and negative, together with acknowledgement of the basis forthose feelings, since they might be displaced from another relationship. The parent's feelings may be influenced by the meaning of the child (Reder et al., 1993; Reder and Duncan, 1995), which reflects how the child holds a special psychological significance for their parent because they are, consciously or unconsciously, associated with other key figures or conflictual events. (Reder, P., Duncan, S, Lucey, C., 2003).Through the inspections it has resulted that mostly fathers use violence but meanwhile children have emotional connection with the fathers. Thus, there is a tension between two recent and important developments in the area of child custody; on one hand, we have come to recognize the important role that fathers play in raising children as a cooperative parent with mothers after separation, however on the other hand, some fathers may not qualify for this role on the grounds of being a perpetrator of partner violence and all that that implies about their parenting (Bancroft \& Silverman, 2002). Evaluation must include even the consequences that the exercises violence by one spouse to the other has on the children while they are witnesses. Even one incident of abuse can adversely affect the emotional stability of a child who witnesses that abuse (Koverola \& Heger, 2003. After the divorce the court must ensure for children's welfare. In practice, though, the principle is often understood to mean that children's welfare is dependent upon maintaining maximum contact with both parents following separation and divorce (Grant, 2005). Theory suggests that violence committed by one parent has consequences in psychological and emotional development of the child, therefore an important part of the evaluation of the children's best interest after the divorce must be focused on bringing clear recommendations in this aspect. 


\section{Research Methodology}

For this research the qualitative method is selected. Through interviews conducted with the judges in charge for family cases in three national courts (Tirana, Durres, and Vlore) will be generated data that will show how they evaluate the violence used by one spouse and its impact on their decisions in order to determine which parent will have the custody of the child after the divorce.

Since the Albanian legal framework does not clearly express this aspect then the decision is taken based on the judge's subjective belief. The selected qualitative research method totally supports the social cases in its deepest meaning from the participant's views on this research. This approach means and emphasizes the exploration, findings and description of this issue. (Bloombering \& Volpre, 2008). The sample selection is done on these courts based not only in the geographical extent but as well on the large number of cases reviewed.

The aim of the study is to identify whether the spouse violence from one partner to another is considered as an influencing factor by the court while taking the decision in order to determine the parental custody after the divorce in Albania.

Objectives of the study are:

To explore the convictions of the judges related to spouse violence and the impact it has on children development.

To understand the opinion of the judges if the spouse violence must be addressed separately or as a crucial issue that affects the decision for determining the custody.

To identify the needs of judges in understanding and applying the children's best interest principle.

The study should answer the research questions: The violence committed by one spouse partner to the other should be considered as a component that affects determination of parental custody or should it be considered separately?

What will be the children consequences if the parental custody will be granted to the parent who has continuously used violence against the other parent?

In this sense, semi-structured questions are prepared in order to ensure a full picture of how the judges apply the children's best interest principle in cases where one the parents is violent.

\subsection{Study participants}

The participants in this study are 12 judges (9 women and 3 men) which are selected intentionally in three national courts in Albania.

Pursuant to the law on the organization of the judiciary, judges in the Albanian courts work under sections belonging to different fields of law. In the study will take part only judges who are part of the family sections, at the courts of first instance, as only these judges have the right to hear cases of divorce and cases regarding child custody. Four judges have been selected for three District courts in order for the sample to be as representative as possible geographically.

\subsection{Research instruments}

The instrument of this research is the interview.There are conducted 12 interviews which are composed with semistructured questions which aim to gather as much data related the facts and the meaning of judges while taking their decissions in determine the best interest of child and parental castody. The qualitative research interview seeks to describe the meanings of central themes in the life world of the subjects. The main task in interviewing is to understand the meaning of what the interviewees say. A qualitative research interview seeks to cover both a factual and a meaning level, though it is usually more difficult to interview on a meaning level. (Kvale,1996). Through this instrument will be possible to analyze data based on judges 'experience and legal predictions. Interviews are particularly useful for getting the story behind a participant's experiences. The interviewer can pursue in-depth information around the topic. Interviews may be useful as follow-up to certain respondents to questionnaires to further investigate their responses. (McNamara,1999)

\section{Findings and Discussions}

The study showed that all interviewed judges accept the fact that spouse violence used by one partner against the other 
is sanctioned by law as a criminal offence and must be treated separately.

Most of the judges think however the violence affects development, education and emotional state of the child, the divorce is a very complex issue related to child well growth and also there is a human right which cannot be denied to any parent to have their children custody for as long as they are not sentenced or the law does not directly forbid them.

During the interviews, judges say that they are obligated to enforce the law and according to Article 155 of the Family Code; they have to identify the material and moral situation of the family, their living conditions and the most appropriate place to live for the children. They cannot require or decide beyond the law boundaries.

The violence against one partner is not a factor or legal component and to this aspect they cannot exclude the parent from the custody after the violent divorce since it is not provided by the law.

One of the interviewed judge's states: "In almost all divorce cases it is found domestic violence mainly by the fathers. Despite this fact, the law guides that we decide on the children's best interest, where in many cases might result in favor of the fathers"

Another interviewed judge states that: she cannot consider as a factor the "violence" used by one parent against the other cannot be proven as long as during the marriage has not denounced any violence. Almost all the spouses during the divorce state that they have been violated with one of the violence forms, but this is done on purpose in order to influence the court decision on children custody.

The court must decide on the best solution and must perform its influence on parents in order for them to agree on their behavior against each other after the divorce. Regarding this fact, the theory suggests that after the divorce process, the parents compromise is required, especially a change of behavior of the abused parent in order to stop the conflict and to increase cooperation between them to facilitate the children's psychological state. However have reached the conclusion that this learned pattern of dealing with her abuser cannot be easily broken, especially in a process that requires compromise. (Imbrogno \& Imbrogno, 2000)

In this meaning the abused parent will continue to have the same attitude toward the abusive parent even after the divorce and this conflictual behavior will continue to have consequences on the children.

Regarding the question of whether the committed violence from one partner to another as a parenting model affects and risks the children to learn or imitate this behavior.

Judges are divided in two opinions: The majority of them think "yes" the violence of one spouse has an impact and can become a parenting model for the children by making them violent.

The rest of judges answered "not necessarily" the argued that: because we are all grown patriarchal family where the father's dominance is accepted as a fact and not all people have become "violent" based on the father's role. They believe that children can become more violent from the media taking as model "characters, exercising violence" than the violent or abusive parent.

Regarding the question whether continuous incidents or all other forms of exercised violence including abuse by one parent to another affects the children's emotional state, most judges believe that: depends on the type of violence exercised. They emphasize the fact that the physical and psychological violence might have more effects than the incidents involving disagreements or disputes in pairs as these are present in every normal family and inevitable.

One of the judges during the interview stated: if we will consider any incident, dispute, or negative attitude of couples as an influencing factor to the children then there would be no divorced families and there would be no normal children. We cannot go to such extremes. I believe that even the children understand that incidents or disputes are normal to a family and sometimes they positively affect and strengthen the couple's relationship after agreements.

This finding conflicts with the literature review where Koverola and Heger say that: Even one incident of abuse can adversely affect the emotional stability of a child who witnesses that abuse.

In this finding the issue that appears is what is meant by "incident" and "abuse" because in different cultures loudly speaking debates are not considered incidents and not providing financial contribution by the housband as a patriarchal model is not considered economic violence but simply as male domination and responsibility related to his family economy.

Also, this finding raises for discussion the fact whether the judges can clearly define the factors that have a direct and indirect impact on children.

Parental conflict can affect children directly by creating stress and anxiety (Kelly, 1998) and indirectly by undermining parenting quality and the children's relationship with one or both parents (Otto et al., 2003)

The theory suggests that the conflicts among couples cannot be ignored or considered as "normal" elements of a family and without consequences on the children, but they should be carefully analyzed by determining the direct impact and the parenting quality. 
Regarding the question whether the principle of the children's best interest is clearly defined by the law and how it is applied, most of the judges believe that: this principle is not clearly defined by the law and it is defined only by one article (art.155 of Family Law) which does not provide concrete actions that the court must perform and does not specify the importance of each evaluation elements.

Related this aspect one of the judges says; Often I am in real difficulties to decide for the parent that will have the children's custody since one of them offers better economic conditions for the children welfare, while the other parent prove a stronger emotional connection. We decide based on our belief but I have doubts if that might be always the best interest for the children.

Regarding the question whether the court performs investigations related dependencies on narcotics or alcohol of the abusive parent judges responded that: these issues are presented in the evaluation reports performed by the evaluation experts but usually claims should be based on evidences that must be provided by the other party (the abused parent)

This finding conflicts with the children's best interest principle. The family code does not provide such investigations related to the abusive spouse but the court must not only evaluate the economic and emotional aspects but also the risk factors or the danger level that one of the parent is dependent on narcotics or alcohol substances. The theory suggests that additionally, complex cases involving the disintegration of a family unit, especially a family with a violent parent, are often fraught with a myriad of destructive factors such as alcohol abuse, suicide attempt, drug abuse (Salomon, Bassuk, \&Huntington, 2002). Assessments are inter-agency and multi-disciplinary. Workers should work individually and collectively to produce assessments which provide the best understanding of parents and issues of child protection (Fowler 2003)

The court cannot simply rely on the fact that if the abused spouse can prove that the violent spouse is drug or alcohol user. Often for these cases there are no evidences but even the abused spouse is unable to provide evidence or to provide counsel in litigation. The court should use its own means in order to perform an evaluation by ensuring that children who will be entrusted to one of the parents for custody will be protected.

The needs that judges have related to the implementation of the children's best interest resulted:

Changes in the Family Code by clearly defining the actions needed to be performed by the court and the evaluation model of this principle by not leaving to much space to subjective decisions but the decisions taken to be pursuant to the law.

Another need is the increase of capacities for the evaluation experts related to their qualifications. Judges suggest that some evaluation procedures and common reporting forms for all employees and phycologists working in the courts must be approved, since it will help the court to have more fair decisions and will avoid the lack of professionalism and incomplete or unrealistic evaluations might negatively affect in determining the decision.

\section{Concluding Remarks}

Based on the research findings we might conclude that spouse violence used by one partner to the other, is not an influencing factor to the court decision in determining the parental custody after divorce in Albania.

Most of the interviewed judges express their belief that the spouse violence has consequences in children development, but this issue should be seen and treated in context with the culture and the family model in general.

The judges think that spouse violence must be treated as a separate issue and the violent partner cannot be excluded from the right of custody of the children.

The needs the judges have in order to better understand and apply the children's best interest principle consist on designing a broader legal framework where are clearly determined the constituent elements of children's best interest.

Judges need that the law clearly defines if the violent partner must be excluded from the right of custody for the children after the divorce.

Another need that will help in decision making is that the evaluation experts must provide professional reports and the final recommendation to the court to be clearly argued.

Increase of inter-institutional cooperation where the court can take data for the parents and the children in cases of divorce and in determining the parental custody.

As conclusion it is obvious that the best interest of child principle resulted not clear in understanding and enforcement by the court in Albania. The legal framework gap has created a fogginess related defining of parental custody after divorce. This situation can precipitate in other consequences regarding children abuse and maltreatment deriving by the inaccurate evaluation of best interest of child principle and irrelevant court decisions related parental 
custody. This article will serve to propound the emergency need of improving procedures of evaluation, assessment and taking decision by the court including necessary legal modifications in order to effectuate the best interest of child principle in Albania.

\section{Recommendations}

It is needed to add a separate chapter within the family code related to the children's best interest which might clearly define the constituent elements and their evaluation model by including concrete actions to be followed by the evaluation experts.

To be determined by the law the restriction on the children's primary custody for all the spouse committing domestic violence.

A unified practice of assessment accordingly to well-defined standards for the evaluation experts must be created.

The capacity of the evaluation experts must be increased and the criteria to be an evaluation expert for the assessment of the parental custody after divorce must be defined.

The case law can be unified in order for the court to judge and decide according to the same standards in every case that a decision regarding the best interests of the child must be made.

A database must be created for any case where violence is ascertained by the police, local authorities, municipalities, and other institutions that can help the court and the evaluation experts to have the relevant and necessary information regarding the parents and children in cases of divorce proceedings and determination of parental custody.

\section{References}

Bloombering. L, \& Volpe, M, (2008) Qualitative Social research

Bentovim, A., Is it possible to work with parental denial?, 14, 270, Reder, P., Duncan, S.,Lucey, C., 2003)

Bancroft, L., \& Silverman, J. (2002). The batterer as a parent: Addressing the impact of partner violence on family dynamics.

Carlson, B. E., McNutt, L. A., Choi, D. Y., \& Rose, I. M. (2002). Intimate partner abuse and mental health: The role of social support and other protective factors. Violence Against Women, 8, 720-745

Edleson, J. L. (1999). The overlap between child maltreatment and woman battering. Violence Against Women, 5, 134-154.

Elrod, L.D., \& Spector, R.G. (2004). A review of the year in family law: Children's issues remain the focus. Family Law Quarterly, 37, $527-575$

Fowler, J, (2003) A Practitioner's Tool for Child Protection and the Assessment of Parents, p. 14

Family Law of Republic of Albania nr. Nr.9062, date 8.5.2003, article 1-6, 130

Imbrogno, A. I.,\&Imbrogno, S. (2000). Mediation in court cases of domestic violence. Families in Society, 81, $392-401$

Jaffe, P. G., Lemon, N. K. D., \& Poisson, S. E. (2003). Child custody and partner violence: A call for safety and accountability.

Constitution law of Republic of Albania Articles 53-54

Kelly, J. (1998). Marital conflict, divorce, and children's adjustment. Child and Adolescent Psychiatric Clinics of North America, 7, 259271

Kvale, Steinar. Interviews An Introduction to Qualitative Research Interviewing, Sage Publications, 1996.

Law nr. 9669, dt18, 12, 2006 "For measures against domestic violence" of republic of Albania.

McNamara, Carter,. General Guidelines for Conducting Interviews, Minnesota, 1999

Otto, R.K., Buffington-Volume, J., \& Edens, J.F. (2003). Child custody evaluation: Research and practice. In A. Goldstein (Ed.), Forensic psychology (pp. 179-208). New York: Wiley.

Penal law of Republic of Albania, NR. 7895, Dt. 27.1.1995, article 130.

Reder, P., Duncan, S.,Lucey, C., (2003) Studies in the Assessment of Parenting

Ragin, D. F., Pilotti, M., Madry, L., Sage, R. E., Bingham, L. E., \& Primm, B. J. (2002). Intergenerational substance abuse and domestic violence as familial risk factors for lifetime attempted suicide among battered women. Journal of Interpersonal Violence, 17, 1027-1045.

Riger, S., Raja, S., \& Camacho, J. (2002). The radiating impact of intimate partner violence. Journal of Interpersonal Violence, 17, 184205.

Salomon, A., Bassuk, S. S., \& Huntington, N. (2002). The relationship between intimate partner violence and the use of addictive substances in poor and homeless single mothers. Violence Against Women, 8, 785-815. 